\title{
A meta-analysis on advantages of peripheral nerve block post-total knee arthroplasty
}

\author{
Di You ${ }^{1}$, Lu Qin ${ }^{2}, \mathrm{Kai} \mathrm{Li}^{1}, \mathrm{Di} \mathrm{Li}^{1}$, Guoqing Zhao ${ }^{1,3}$, and Longyun $\mathrm{Li}^{1}$ \\ 'China-Japan Union Hospital of Jilin University, Changchun, Jilin, China \\ ${ }^{2}$ Center for Applied Statistical Research and College of Mathematics, Jilin University, Changchun, Jinlin, China \\ ${ }_{3}^{3}$ Jilin University, Changchun, China
}

Received December 2, 2020

Revised March 8, 2021

Accepted March 8, 2021

Handling Editor: Hyun Kang

\section{Correspondence}

Guoqing Zhao

Jilin University, 2699 Qianjin Street,

Changchun 130012, Jilin, China

Tel: +8613500886187

E-mail: guoqing@jlu.edu.cn

Longyun $\mathrm{Li}$

China-Japan Union Hospital of Jilin University, 126 Xiantai Street, Changchun 130033, Jilin, China

Tel: +8613514467611

E-mail: longyun@jlu.edu.cn
Background: Postoperative pain management is crucial for patients undergoing total knee arthroplasty (TKA). There have been many recent clinical trials on post-TKA peripheral nerve block; however, they have reported inconsistent findings. In this meta-analysis, we aimed to comprehensively analyze studies on post-TKA analgesia to provide evidence-based clinical suggestions.

Methods: We performed a computer-based query of PubMed, Embase, the Cochrane Library, and the Web of Science to retrieve related articles using neurothe following search terms: nerve block, nerve blockade, chemodenervation, chemical neurolysis, peridural block, epidural anesthesia, extradural anesthesia, total knee arthroplasty, total knee replacement, partial knee replacement, and others. After quality evaluation and data extraction, we analyzed the complications, visual analogue scale (VAS) score, patient satisfaction, perioperative opioid dosage, and rehabilitation indices. Evidence was rated using the Grading of Recommendations Assessment, Development, and Evaluation approach.

Results: We included 16 randomized controlled trials involving 981 patients (511 receiving peripheral nerve block and 470 receiving epidural block) in the final analysis. Compared with an epidural block, a peripheral nerve block significantly reduced complications. There were no significant between-group differences in the postoperative VAS score, patient satisfaction, perioperative opioid dosage, and rehabilitation indices.

Conclusions: Our findings demonstrate that the peripheral nerve block is superior to the epidural block in reducing complications without compromising the analgesic effect and patient satisfaction. Therefore, a peripheral nerve block is a safe and effective postoperative analgesic method with encouraging clinical prospects.

Key Words: Analgesia, Epidural; Analgesics, Opioid; Arthroplasty, Replacement, Knee; Evidence-Based Medicine; Femoral Nerve; Meta-Analysis; Nerve Block; Pain Management; Pain, Postoperative.

\section{INTRODUCTION}

Total knee arthroplasty (TKA) is the most effective treatment for end-stage knee osteoarthritis and rheumatoid ar- thritis [1]. During the early post-TKA period, $60 \%$ and $30 \%$ of patients experience severe and moderate pain, respectively [2]. Postoperative pain affects the patient's physiological state, rest and sleep, triggers anxiety, increases the (c) This is an open-access article distributed under the terms of the Creative Commons Attribution Non-Commercial License (http://creativecommons.org/licenses/by-nc/4.0/), which permits unrestricted non-commercial use, distribution, and reproduction in any medium, provided the original work is properly cited.

(C) The Korean Pain Society, 2021
Author contributions: Di You: Writing/manuscript preparation; Lu Qin: Writing/manuscript preparation; Kai Li: Methodology; Di Li: Investigation; Guoqing Zhao: Methodology; Longyun Li: Data curation. 
risk of complications (including venous thrombosis and pneumonia), affects postoperative efficacy and functional recovery, prolongs hospital stays, increases medical costs, and reduces patient satisfaction and early-stage quality of life [3-5].

Increasing attention is being paid to post-TKA pain relief. The traditional patient-controlled analgesia, using morphine, often involves many opioid-related side effects. Epidural analgesia and peripheral nerve block are two additional commonly used methods for post-TKA analgesia. An epidural block effectively reduces the intraoperative use of analgesic and opioid drugs. However, the drugs used for such block have a high incidence of complications, including nausea/vomiting, dizziness, itching, and urinary retention. Moreover, they have a high risk of inducing severe neurological complications [6]. Zinkus et al. [7] proposed that the femoral nerve block has a good postTKA analgesic effect, and is helpful to patients in achieving early functional recovery. Runge et al. [8] showed that the obturator nerve block could significantly relieve postoperative chronic knee pain. Some studies have shown that the adductor nerve block could be used to relieve pain in patients after TKA. Its analgesic effect is similar to that of the femoral nerve block, but it does not affect the quadriceps femoris muscle strength as much as the femoral nerve block does $[9,10]$.

Previous studies have reported that the epidural block is clinically superior to the peripheral nerve block in reducing pain [11]. Contrastingly, other studies have demonstrated that the peripheral nerve block had superior clinical efficacy compared to the epidural block $[12,13]$. We accumulated data from the included 16 randomized controlled trials, and compared the clinical outcomes between the peripheral nerve block and epidural block for post-TKA, aiming for a more comprehensive understanding of the differences in efficacy between them. The clinical outcomes included complications, visual analogue scale (VAS) score, patient satisfaction, perioperative opioid dosage, and rehabilitation indices.

\section{MATERIALS AND METHODS}

This meta-analysis was performed following the Preferred Reporting Items for Systematic Reviews and Meta-Analyses (PRISMA) statement [14]. We registered our study in the International Prospective Register of Systematic Reviews (CRD42020163406) on April 28, 2020. All analyses were based on previous published studies; thus, no ethical approval and patient consent are required.

\section{Search methods for study identification}

The search strategy was formulated following the standards of the Cochrane collaboration. We performed a manual online search through PubMed, Embase, Cochrane, and the Web of Science databases, to retrieve related studies, using the following search terms: nerve block, nerve blockade, chemodenervation, chemical neurolysis, peridural block, epidural anesthesia, extradural anesthesia, total knee arthroplasty, total knee replacement, partial knee replacement, and others. The search also used Boolean operators.

\section{Eligibility criteria}

1) Inclusion criteria

We used the following inclusion criteria:

- Studies involving patients with post-TKA in American Society of Anesthesiologists (ASA) categories I-III, without restrictions for age, race, or nationality.

- Studies involving an experimental group that underwent peripheral nerve blocks (femoral, femoral + tibial, adductor canal, and so on) and a control group that underwent epidural blocks. The primary anesthesia could be simple general, simple spinal, or general + spinal.

- Randomized controlled trials with no language limitations.

- Studies reporting at least one of the following indicators: postoperative complications (nausea and vomiting, hypotension, urinary retention, pruritus, and sedation), pain score, patient satisfaction, perioperative opioid dosage, and rehabilitation indices.

- Studies reporting accurate and reliable data that could be transformed into binary or continuous variables to represent each index.

\section{2) Exclusion criteria}

We employed the following exclusion criteria:

- Studies that assessed animals or corpses

- TKA studies that included knee arthroscopy or hip joint operation and data on the TKA that could not be extracted independently.

- Case reports, reviews, retrospective studies, or conference papers without full text.

- Reports with data that could not be extracted or converted into valid data for meta-analysis. 


\section{Measurement index}

1) Primary outcome measures

- Pain score: Postoperative pain control is the most important outcome indicator. Mild pain allows limited physiotherapy, which in turn contributes to a faster recovery of knee function $[15,16]$. Severe postoperative pain can induce other complications, including thrombosis, infection, poor activity, and prolonged hospital stay, which increases medical costs [17]. We compared the post-TKA VAS pain score at three postoperative time slots, i.e., 0-12, 12-24, and 24-48 hours. Moreover, pain intensity assessed on a 10-mm VAS.

\section{2) Secondary outcome measures}

- Complications: This is a paramount factor affecting clinical postoperative analgesia, quality of life, and acceptance of the analgesia. Common severe complications include nausea and vomiting, hypotension, urinary retention, pruritus, and sedation.

- Patient satisfaction: Postoperative patient satisfaction is a major subjective index for measuring the analgesic effect.

- Perioperative opioid dosage: Opioids are the main drugs used for surgical analgesia, including fentanyl, oxycodone, piritramide, and morphine. However, their serious complications are a concern for clinicians $[18,19]$. We analyzed the opioids used during and after surgery.

- Rehabilitation indices: Good analgesic treatment allows patients who undergo TKA, to experience more active rehabilitation treatment. Mistimed functional rehabilitation could influence its eventual clinical efficacy, with some patients having to undergo a secondary release surgery. This causes a heavy burden on the patients and their families. Therefore, rehabilitation indices are major indirect indicators for the effect of analgesia. We analyzed the length of hospital stay and range of active knee flexion.

\section{Assessment of the methodological quality}

Two researchers (DY and LQ) independently assessed the methodological quality of the included studies and used the Cochrane's tool [20] to assess their bias risk. Disagreements between the two researchers were resolved by consulting a third researcher (GQZ) to reach a consensus.

\section{Data collection}

Two researchers (DY and LQ) independently extracted relevant data, using pre-designed standard data extraction forms. Any disagreements were resolved, as mentioned above. In the case of incomplete data in an article, the corresponding author was contacted via e-mail or other means; however, we did not receive any replies. When the standard deviation (SD) was missing and the corresponding author could not be reached, we referred to the article by Hou et al. [21], we used the method described for range or median estimation, or the method described in the $\mathrm{Co}$ chrane Handbook for Systematic Reviews of Interventions [22]. The possible SD was estimated from the confidence interval (CI).

\section{Statistical analysis}

RevMan 5.3 (Cochrane, London, UK) and STATA 14.0 (StataCorp., College Station, TX) software were used for the statistical analysis. This program, by the International Cochrane Collaboration Network, is used to produce and store Cochrane systematic reviews. It is produced and updated by the Nordic Cochrane Center. The $I^{2}$ test was used to quantify the degree of heterogeneity. The randomeffect model was employed when $I^{2}$ was $>50 \%$, which indicates significant heterogeneity; otherwise, the fixedeffect model was used. The risk ratio (RR) and standardized mean difference (SMD) were used to analyze binary and continuous variables, respectively [23]. The 95\% CI estimates and hypothesis test results for each variable are presented on forest plots. When there was significant heterogeneity, a sensitivity analysis was conducted by excluding the studies one-by-one and repeating the analysis. We performed a subgroup analysis based on the different primary anesthetic methods (general anesthesia, spinal anesthesia, and general + spinal anesthesia). Publication bias was assessed using Egger's test when $\geq 10$ studies were included. Finally, the results were graded using the Grades of Recommendations Assessment, Development and Evaluation (GRADE) profile software. Nineteen countries and international organizations, including the World Health Organization, established the GRADE working group, and formally launched the GRADE evidence quality grading and recommendation strength system in 2004. It can be downloaded and installed at no cost from the Cochrane cooperation network (http://www.gradeworkinggroup. org). 


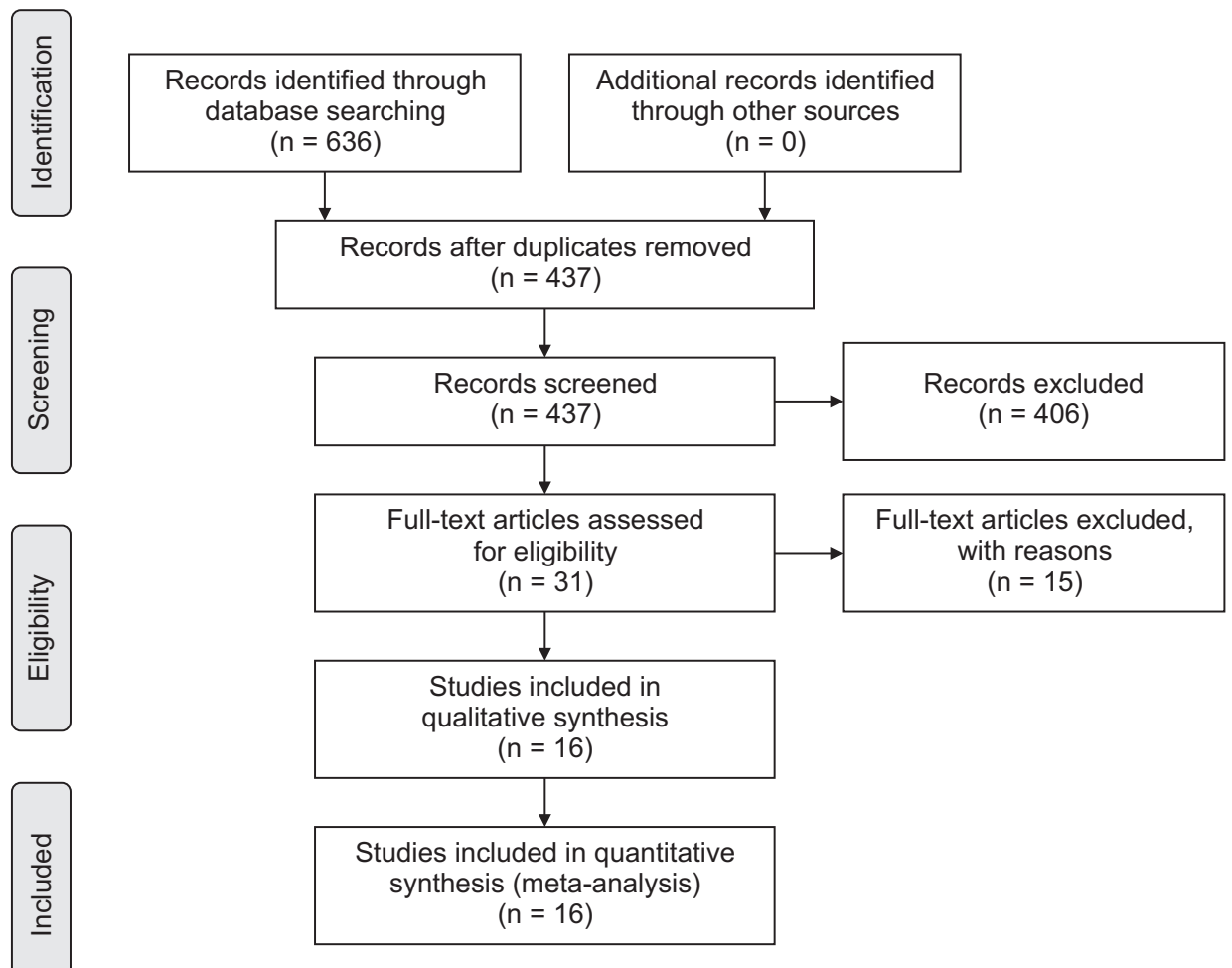

Fig. 1. Flowchart of the study selection process.

\section{RESULTS}

\section{Search results and characteristics of the selected studies}

We retrieved 636 studies from the databases using the aforementioned search strategy. EndNote X9 software (Thomson Corp., Stanford, CT) was used to remove duplicates. After reading the titles, abstracts, and full text, we included in the meta-analysis 16 eligible randomized controlled trials that involved 981 patients, 511 in the experimental group, and 470 in the control group (Fig. 1). Table 1 shows the basic characteristics of the included studies. Table 2 shows the baseline demographic and clinical characteristics of the studied population.

\section{Methodology evaluation}

Fig. 2 shows the risk bias evaluation of the selected 16 randomized controlled trials.

\section{Clinical outcomes}

1) Adverse effects

(1) Nausea and vomiting

Ten studies [2,13,24-31] involving 526 patients reported on nausea and vomiting. 262 in the experimental group, 264 in the control group. There was no among-study heterogeneity $\left(I^{2}=0 \%, P=0.86\right)$; therefore, the fixed-effect model was used. The experimental group had a significantly lower incidence of nausea and vomiting than the control group (RR $=0.62,95 \% \mathrm{CI}[0.44$ to 0.88$], P=0.007$ ) (Fig. 3). Table 3 presents Egger's test results $(P=0.448,95 \%$ CI $[-3.25$ to 1.58$]$ ), which shows no obvious publication bias. The quality of the evidence was determined as being of a high grade by the GRADE Profile (Supplementary Table 1).

\section{(2) Hypotension}

Twelve studies [2,13,25-30,32-35] involving 705 patients reported on hypotension, with 350 in the experimental group, and 355 in the control group. There was no amongstudy heterogeneity $\left(I^{2}=0 \%, P=0.76\right)$; therefore, the fixedeffect model was used. The experimental group had a significantly lower incidence of hypotension than the control group (RR $=0.64,95 \% \mathrm{CI}$ [0.48 to 0.85], $P=0.002$ ) (Fig. 4). Table 4 presents Egger's test results $(P=0.069,95 \%$ CI $[-2.80$ to 0.13$]$ ), which shows no obvious publication bias. The quality of the evidence was determined as being of a moderate grade by the GRADE Profile (Supplementary Table 1).

(3) Urinary retention

Eight studies $[2,13,25-27,30,31,34]$ involving 370 patients 


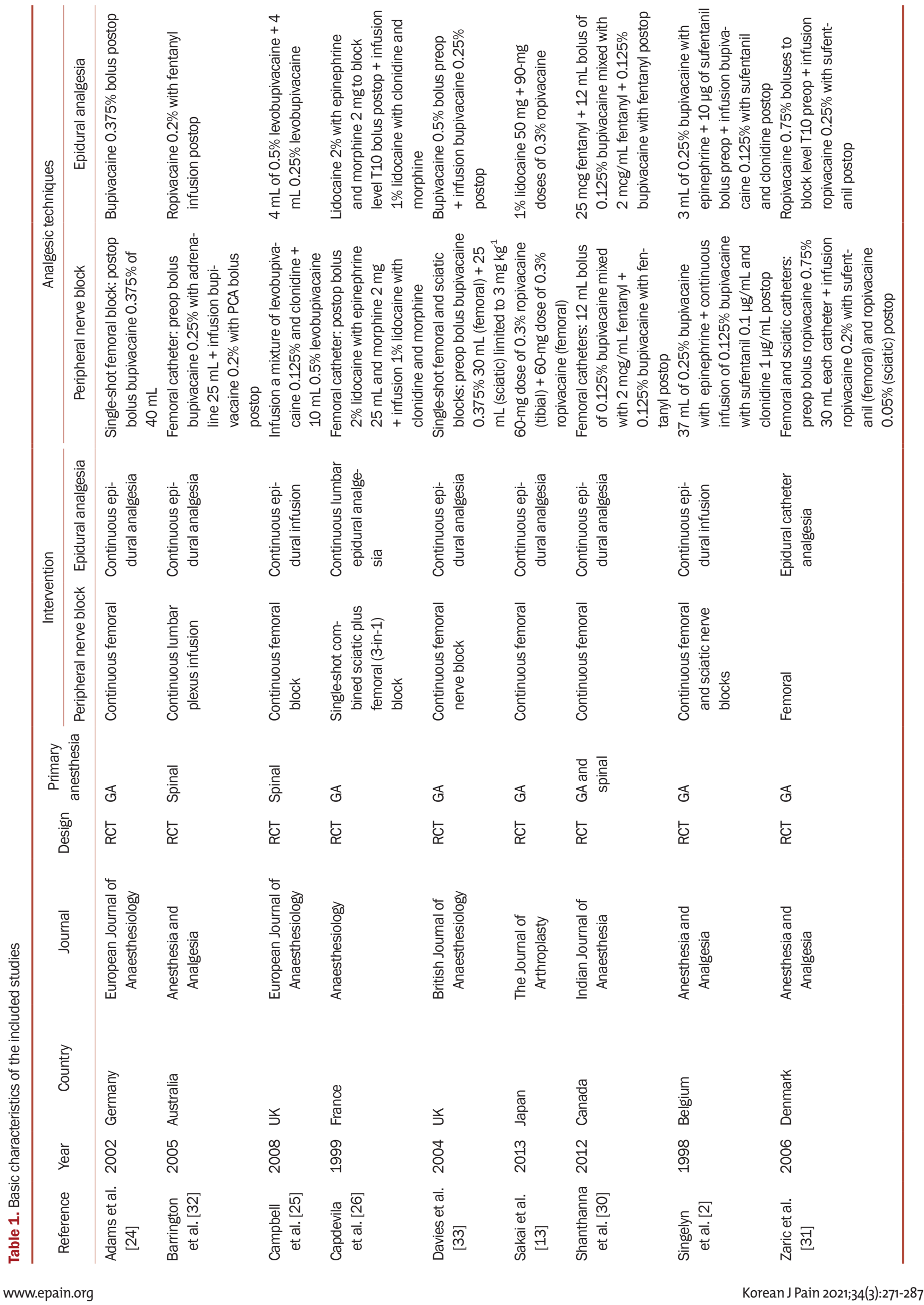




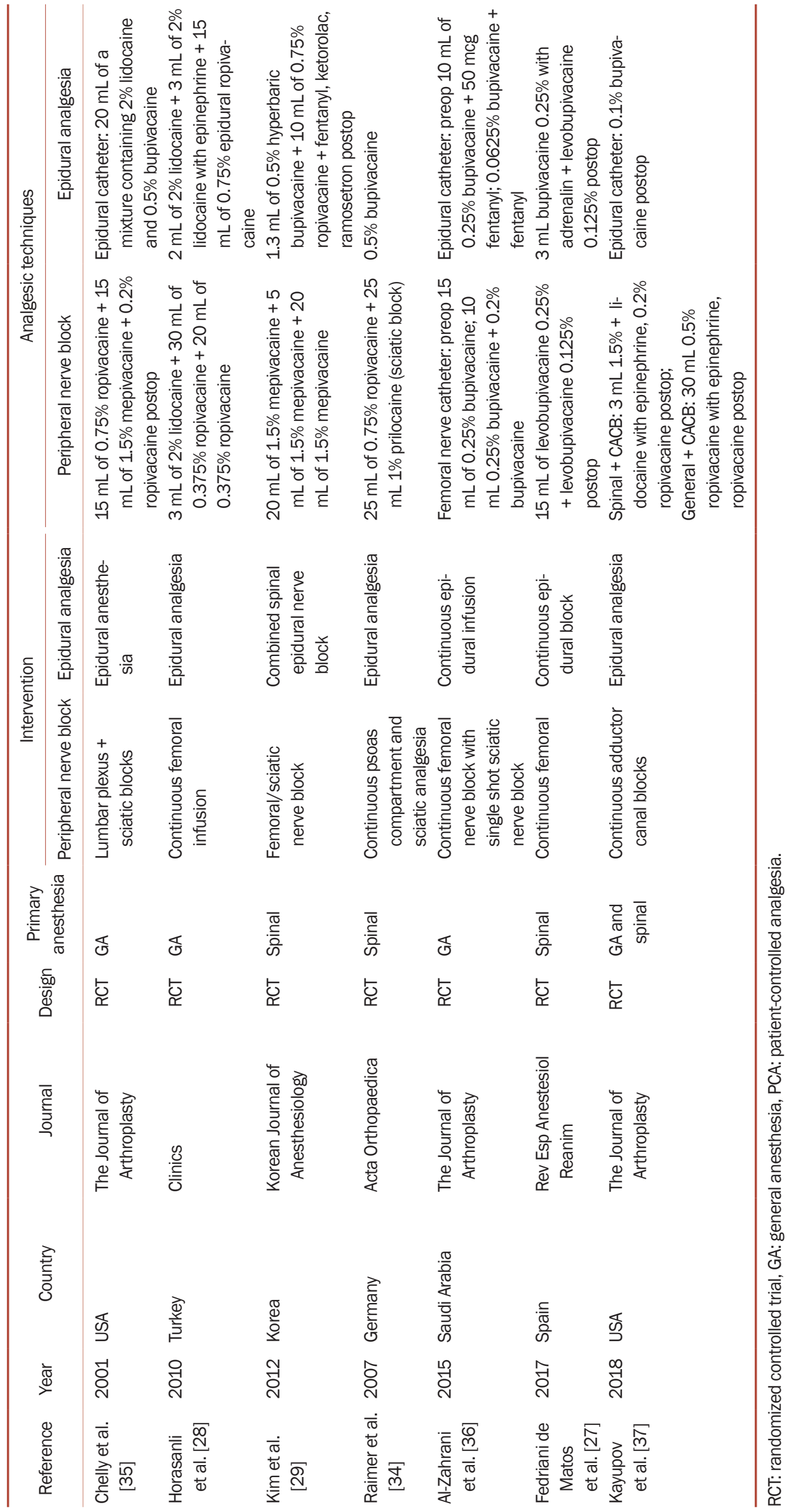




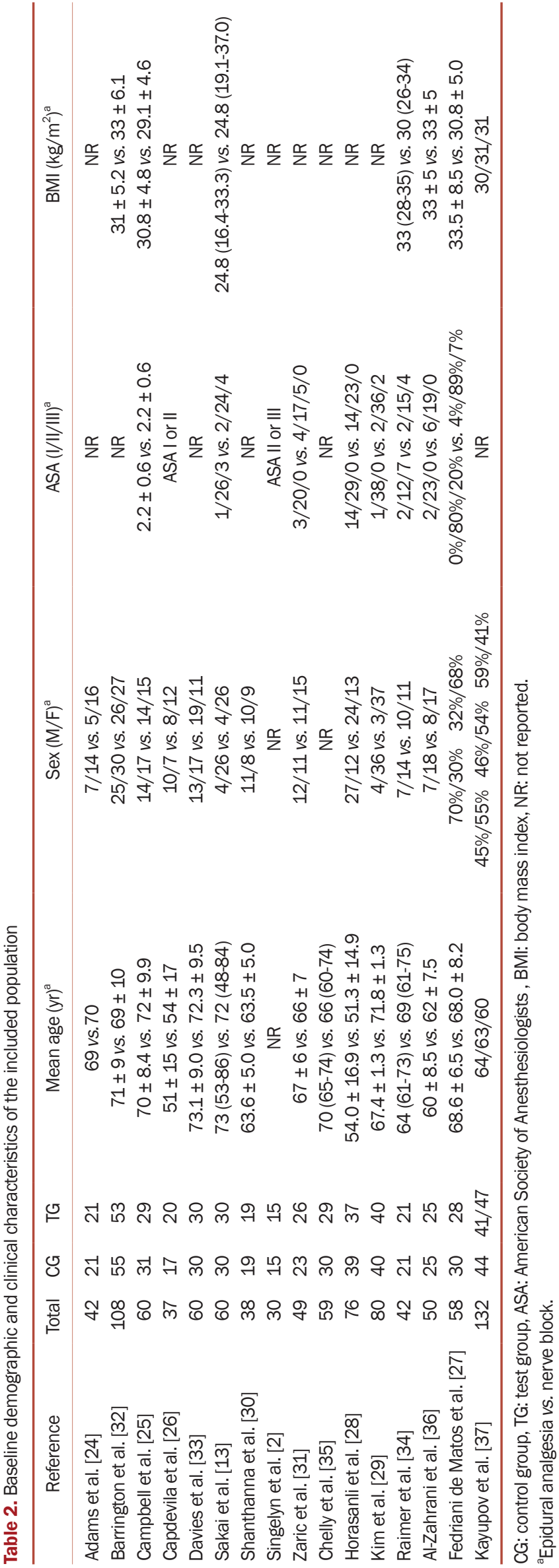

reported on urinary retention, with 185 in the experimental group, and 185 in the control group. There was no among-study heterogeneity $\left(I^{2}=5 \%, P=0.39\right)$; therefore, the fixed-effect model was used. The experimental group showed a significantly lower incidence of urinary retention than the control group ( $\mathrm{RR}=0.30,95 \% \mathrm{CI}$ [0.17 to 0.53], $P<0.001$ ) (Fig. 5). The quality of the evidence was determined as being of a moderate grade by the GRADE Profile (Supplementary Table 1).

\section{(4) Pruritus}

Five studies $[26,27,29,31,34]$ involving 266 patients reported on pruritus 135 in the experimental group, 131 in the control group. There was no among-study heterogeneity ( $I^{2}$ $=0 \%, P=0.81$ ); therefore, the fixed-effect model was used. The experimental group showed a significantly lower incidence of pruritus than the control group ( $R R=0.14,95 \%$ CI [0.03 to 0.59 ], $P<0.008$ ) (Fig. 6). The quality of the evidence was determined as being of a moderate grade by the GRADE Profile (Supplementary Table 1).

\section{(5) Sedation}

Four studies $[26,27,29,31]$ involving 224 patients reported on sedation, with 114 in the experimental group, and 110 in the control group. There was no among-study heterogeneity $\left(I^{2}=0 \%, P=0.82\right)$; therefore, the fixed-effect model was used. There was no between-group difference in the sedation incidence ( $\mathrm{RR}=2.02,95 \% \mathrm{CI}[0.32$ to 12.92$], P=$ 0.46) (Fig. 7). The quality of the evidence was determined as being of a moderate grade by the GRADE Profile (Supplementary Table 1).

\section{2) VAS score}

\section{(1) 0-12 hours}

Eight studies [2,24,27,29-31,34,36] involving 389 patients reported on the VAS score within 0-12 hours after the surgery, with 195 in the experimental group, and 194 in the control group. There was among-study heterogeneity $\left(I^{2}=58 \%, P=0.02\right)$; therefore, the random-effect model was used. There was no between-group difference in the VAS score (SMD $=0.38,95 \%$ CI $[-0.00$ to 0.76$], P=0.05$ ) (Fig. 8). Sensitivity analysis revealed that after removing the study by Singelyn et al. [2], $I^{2}$ was decreased to $0 \%$ without changing the conclusion (SMD $=0.21,95 \% \mathrm{CI}[-0.01$ to $0.44], P=0.57$ ) (Supplementary Fig. 1). Sub-group analysis revealed no between-subgroup heterogeneity $\left(I^{2}=20.1 \%, P\right.$ $=0.29$ ) (Supplementary Fig. 2). The quality of the evidence was determined as being of a low grade by the GRADE Pro- 

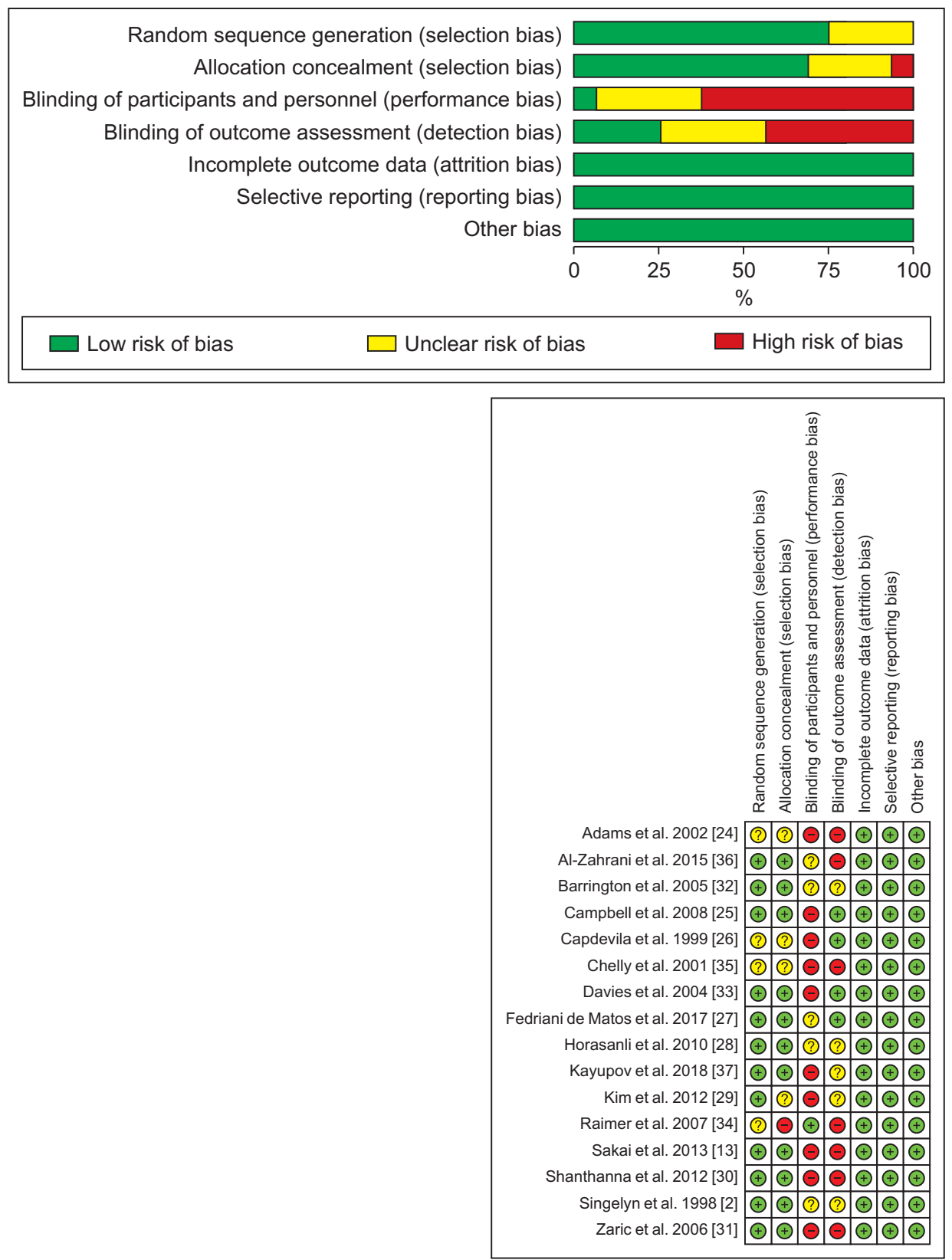

Fig. 2. Risk of bias graph and summary.

file (Supplementary Table 2).

\section{(2) 12-24 hours}

Eleven studies [2,26,27,29-34,36,37] involving 636 patients reported the VAS score within 12-24 hours after the surgery, with 318 in the experimental group, and 318 in the control group. There was among-study heterogeneity $\left(I^{2}\right.$ $=93 \%, P<0.001)$; therefore, the random-effect model was used. There was no between-group difference in the VAS score (SMD $=-0.01,95 \%$ CI [-0.73 to 0.71$], P=0.97$ ) (Fig. 9). Sensitivity analysis revealed no heterogeneity source, and there was no between-group heterogeneity. The subgroup analysis result was $I^{2}=0 \%, P=0.65$ (Supplementary Fig.
3), this indicates that the heterogeneity source was not significantly related to the anesthesia mode, but its source could not be determined. Table 5 presents Egger's test results ( $P=0.851,95 \% \mathrm{CI}[-7.97$ to 9.36$])$, which shows no obvious publication bias. The quality of the evidence was determined as being of a low grade by the GRADE Profile (Supplementary Table 2).

\section{(3) 24-48 hours}

Ten studies [2,26,27,29-32,34,36,37] involving 578 patients reported on the VAS score within 24-48 hours after the surgery, with 289 in the experimental group, and 289 in the control group. There was among-study heterogeneity 


\begin{tabular}{|c|c|c|c|c|c|c|c|c|c|}
\hline \multirow{2}{*}{$\begin{array}{l}\text { Study or subgroup } \\
\text { Adams et al. } 2002[24]\end{array}$} & \multicolumn{2}{|c|}{$\begin{array}{l}\text { Experimental } \\
\text { Events Total }\end{array}$} & \multicolumn{2}{|c|}{ Control } & Weight & $\begin{array}{c}\text { Risk ratio } \\
\mathrm{M}-\mathrm{H} \text {, fixed, } 95 \% \mathrm{Cl} \\
\end{array}$ & \multicolumn{2}{|c|}{$\begin{array}{c}\text { Risk ratio } \\
\mathrm{M}-\mathrm{H} \text {, fixed, } 95 \% \mathrm{Cl}\end{array}$} & \\
\hline & 9 & 21 & 17 & 21 & $29.1 \%$ & $0.53[0.31,0.90]$ & --1 & & \\
\hline Campbell et al. 2008 [25] & 9 & 26 & 12 & 30 & $19.1 \%$ & $0.87[0.44,1.72]$ & 一 & - & \\
\hline Capdevila et al. $1999[26]$ & 1 & 20 & 3 & 17 & $5.5 \%$ & $0.28[0.03,2.48]$ & & & \\
\hline Fedriani de Matos et al. 2017 [27] & 2 & 28 & 2 & 30 & $3.3 \%$ & $1.07[0.16,7.10]$ & & & \\
\hline Horasanli et al. 2010 [28] & 1 & 37 & 4 & 39 & $6.7 \%$ & $0.26[0.03,2.25]$ & & — & \\
\hline Kim et al. 2012 [29] & 1 & 40 & 2 & 40 & $3.4 \%$ & $0.50[0.05,5.30]$ & & & \\
\hline Sakai et al. 2013 [13] & 4 & 30 & 6 & 30 & $10.3 \%$ & $0.67[0.21,2.13]$ & & - & \\
\hline Shanthanna et al. 2012 [30] & 2 & 19 & 5 & 19 & $8.6 \%$ & $0.40[0.09,1.81]$ & & - & \\
\hline Singelyn et al. 1998 [2] & 5 & 15 & 4 & 15 & $6.8 \%$ & $1.25[0.41,3.77]$ & - & & \\
\hline Zaric et al. 2006 [31] & 2 & 26 & 4 & 23 & $7.3 \%$ & $0.44[0.09,2.20]$ & - & - & \\
\hline Total $(95 \% \mathrm{Cl})$ & & 262 & & 264 & $100.0 \%$ & $0.62[0.44,0.88]$ & $>$ & & \\
\hline \multirow{3}{*}{\multicolumn{6}{|c|}{$\begin{array}{l}\text { Heterogeneity: } \text { chi }^{2}=4.76, \mathrm{df}=9(P=0.86) ; I^{2}=0 \% \\
\text { Test for overall effect: } Z=2.68(P=0.007)\end{array}$}} & + & & & \\
\hline & & & & & & 0.005 & $0.1 \quad 1$ & 110 & 200 \\
\hline & & & & & & Favor & perimental] & Favors [ & \\
\hline
\end{tabular}

Fig. 3. Forest plot for the incidence of nausea and vomiting after nerve block vs. epidural block. M-H: Mantel-Haenszel, Cl: confidence interval, df: degree of freedom.

Table 3. Egger's test of nausea and vomiting

\begin{tabular}{lrrrrr}
\hline Std_Eff & Coef. & Std. Err. & $t$ & $P>|t|$ & $95 \% \mathrm{Cl}$ \\
\hline Slope & 0.006 & 0.880 & 0.01 & 0.994 & $-2.022,2.035$ \\
Bias & -0.836 & 1.049 & -0.80 & 0.448 & $-3.255,1.583$ \\
\hline
\end{tabular}

Std_Eff: standardized effect, Coef.: coefficient, Std. Err.: standard error, Cl: confidence interval.

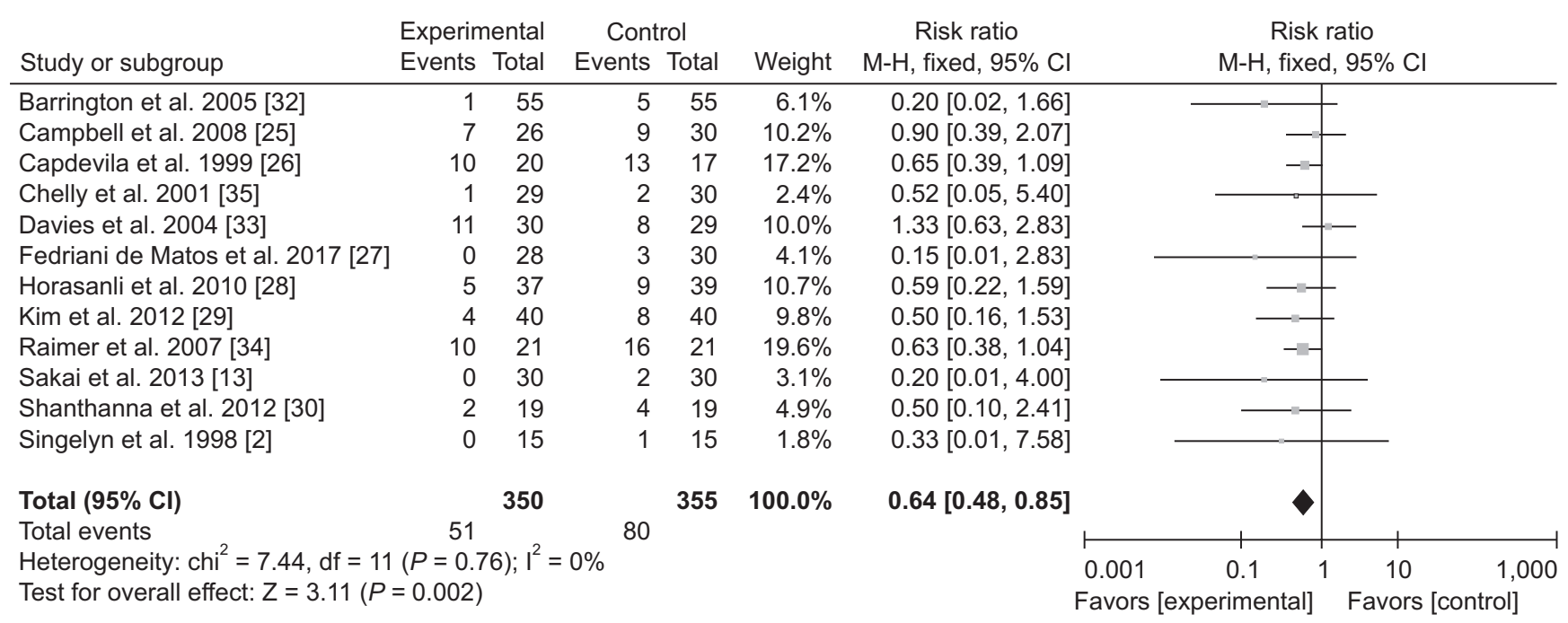

Fig. 4. Forest plot for the incidence of hypotension after nerve block vs. epidural block. M-H: Mantel-Haenszel, Cl: confidence interval, df: degree of freedom.

Table 4. Egger's test of hypotension

\begin{tabular}{cccccc}
\hline Std_Eff & Coef. & Std. Err. & $t$ & $P>\mid \mathrm{tl}$ & $95 \% \mathrm{Cl}$ \\
\hline Slope & 0.376 & 0.497 & 0.76 & 0.469 & $-0.748,1.500$ \\
Bias & -1.337 & 0.648 & -2.06 & 0.069 & $-2.803,0.130$ \\
\hline
\end{tabular}

Std_Eff: standardized effect, Coef.: coefficient, Std. Err.: standard error, Cl: confidence interval. 


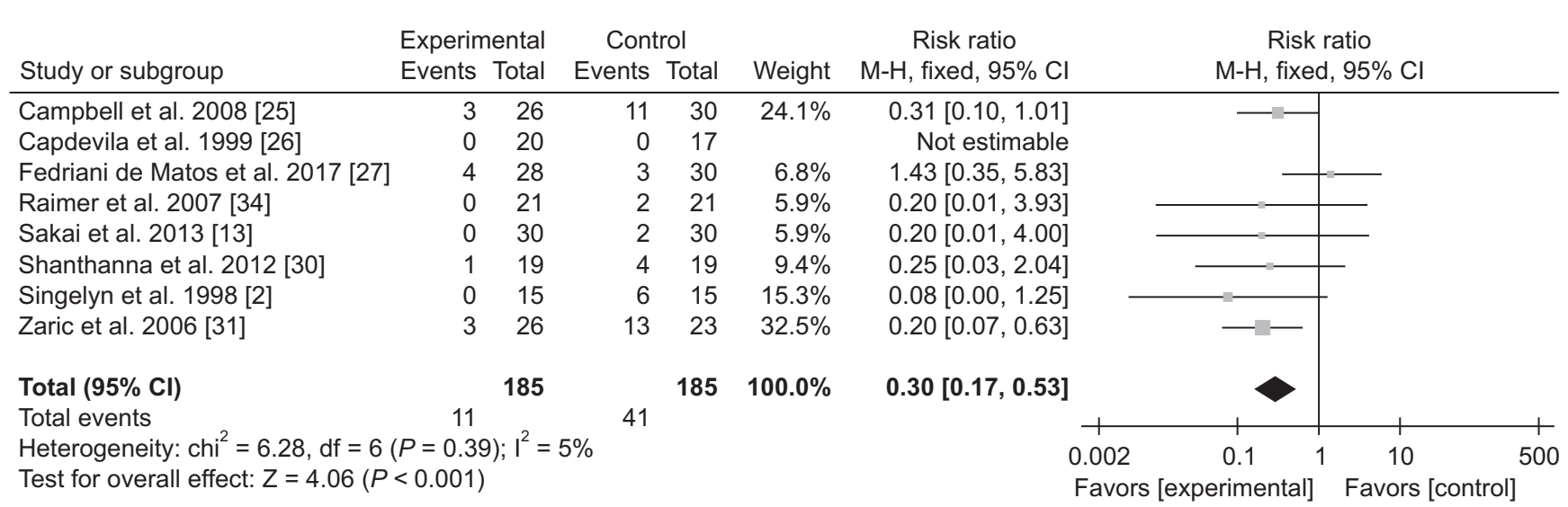

Fig. 5. Forest plot for the incidence of urinary retention after nerve block vs. epidural block. M-H: Mantel-Haenszel, Cl: confidence interval, df: degree of freedom.

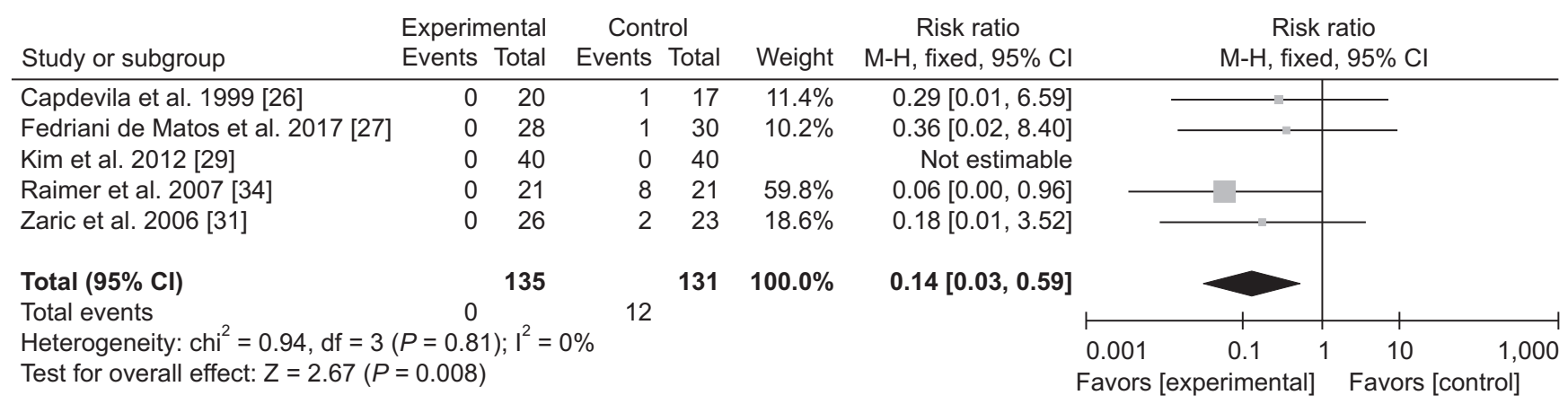

Fig. 6. Forest plot for the incidence of pruritus after nerve block vs. epidural block. M-H: Mantel-Haenszel, Cl: confidence interval, df: degree of freedom.

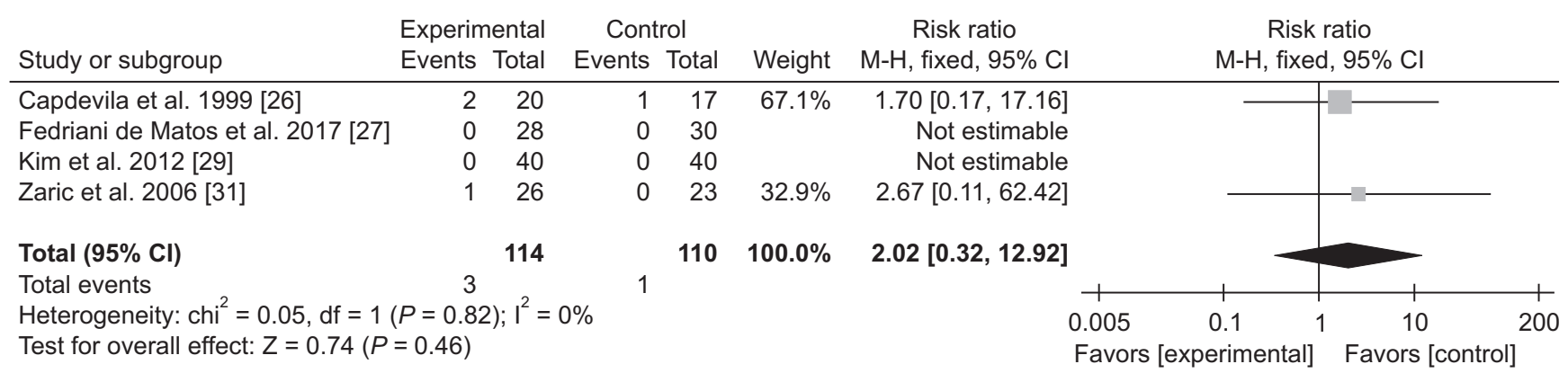

Fig. 7. Forest plot for the incidence of sedation after nerve block vs. epidural block. M-H: Mantel-Haenszel, Cl: confidence interval, df: degree of freedom.

$\left(I^{2}=68 \%, P<0.001\right)$; therefore, the random-effect model was used. There was no between-group difference in the VAS score (SMD $=-0.23,95 \%$ CI $[-0.65$ to -0.18$], P=0.26$ ) (Supplementary Fig. 4). Sensitivity analysis revealed that after removing the study by Kim et al., [29], $I^{2}$ decreased to $34 \%$, with the experimental group having a significantly lower VAS score than the control group (SMD $=-0.27,95 \%$ CI [ -0.49 to -0.05$], P=0.02$ ) (Fig. 10). Subgroup analysis revealed no between-subgroup heterogeneity $\left(I^{2}=0 \%, P=\right.$ 0.97) (Supplementary Fig. 5). Table 6 presents Egger's test results $(P=0.186,95 \%$ CI [-118.21 to 69.28$])$, which shows no obvious publication bias. The quality of the evidence was determined as being of a low grade by the GRADE Profile (Supplementary Table 2).

\section{3) Patient satisfaction}

Four studies $[27,28,36,37]$ involving 316 patients reported on patient satisfaction, with 178 in the experimental group, and 138 in the control group. There was no among-study heterogeneity $\left(I^{2}=0 \%, P=0.69\right)$; therefore, the fixed-effect model was used. There was no between-group difference in the patient satisfaction ( $\mathrm{RR}=1.06,95 \% \mathrm{CI}$ [0.94 to 1.18], $P=0.34$ ) (Fig. 11). The quality of the evidence was deter- 


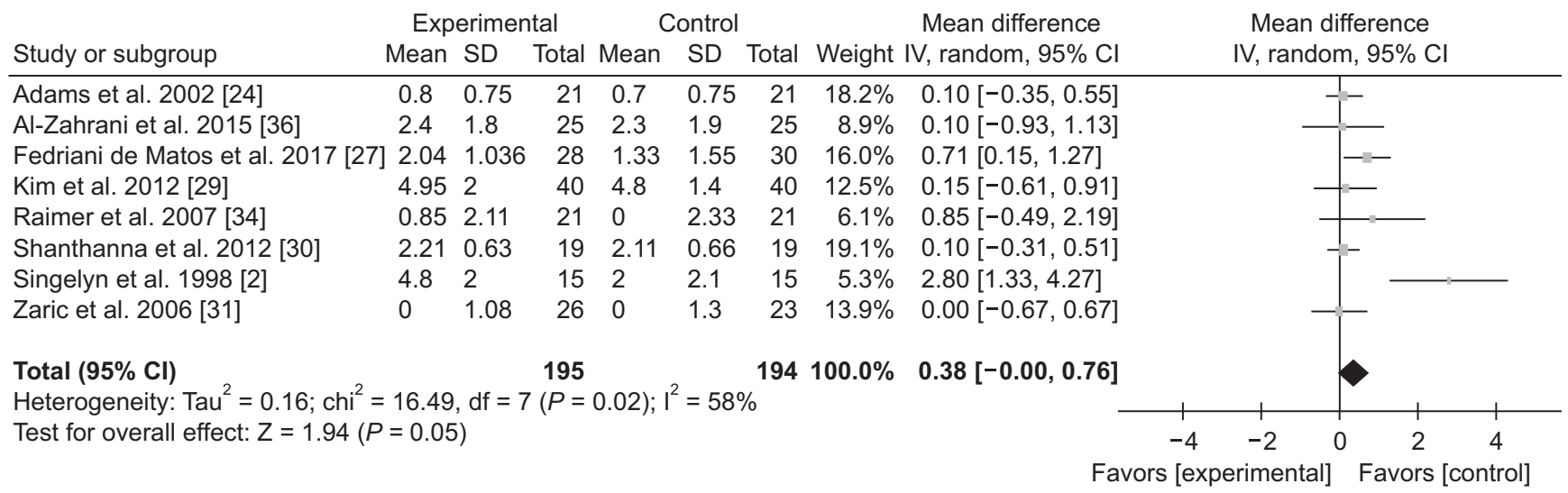

Fig. 8. Forest plot for the visual analogue scale score during 0-12 hours after surgery after nerve block vs. epidural block. SD: standard deviation, IV: inverse variance, $\mathrm{Cl}$ : confidence interval, df: degree of freedom.

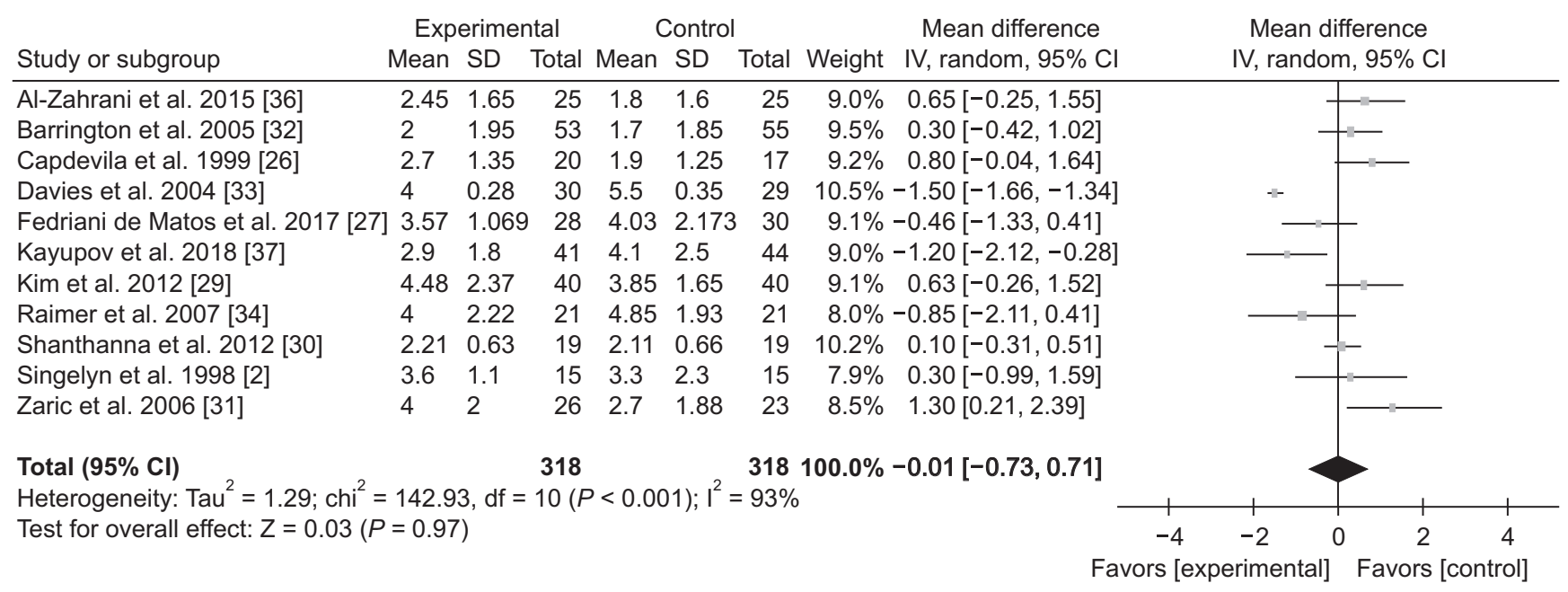

Fig. 9. Forest plot for the visual analogue scale score within 12-24 horrs after nerve block vs. epidural analgesia. SD: standard deviation, IV: inverse variance, Cl: confidence interval, df: degree of freedom.

Table 5. Egger's test of the visual analogue scale score within 12-24 hours

\begin{tabular}{cccccc}
\hline Std_Eff & Coef. & Std. Err. & $t$ & $P>\mid \mathrm{tl}$ & $95 \% \mathrm{Cl}$ \\
\hline Slope & -1.344 & 0.897 & -1.50 & 0.185 & $-3.539,0.851$ \\
Bias & 0.696 & 3.543 & 0.20 & 0.851 & $-7.973,9.365$ \\
\hline
\end{tabular}

Std_Eff: standardized effect, Coef.: coefficient, Std. Err.: standard error, Cl: confidence interval.

mined as being of a moderate grade by the GRADE Profile (Supplementary Table 3).

\section{4) Opioid consumption}

Seven studies $[25,27,31-34,36]$ involving 534 patients reported the perioperative opioid dosage, with 265 in the experimental group, and 269 in the control group. One study [36] only reported the intraoperative opioid dosage, while three studies $[31,33,34]$ only reported the postoperative opioid dosage. There was significant among-study hetero- geneity $\left(I^{2}=79 \%, P<0.001\right)$; therefore, the random-effect model was used. The opioid dosage in the experimental group was insignificantly lower than the control group (SMD $=-2.02,95 \%$ CI $[-8.4$ to 4.36$], P=0.54$ ) (Fig. 12). Sensitivity analysis did not reveal the source of the heterogeneity; moreover, subgroup analysis revealed no betweensubgroup heterogeneity $\left(I^{2}=0 \%, P=0.57\right.$ ) (Supplementary Fig. 6). The quality of the evidence was determined as being of a very low grade by the GRADE Profile (Supplementary Table 4). 


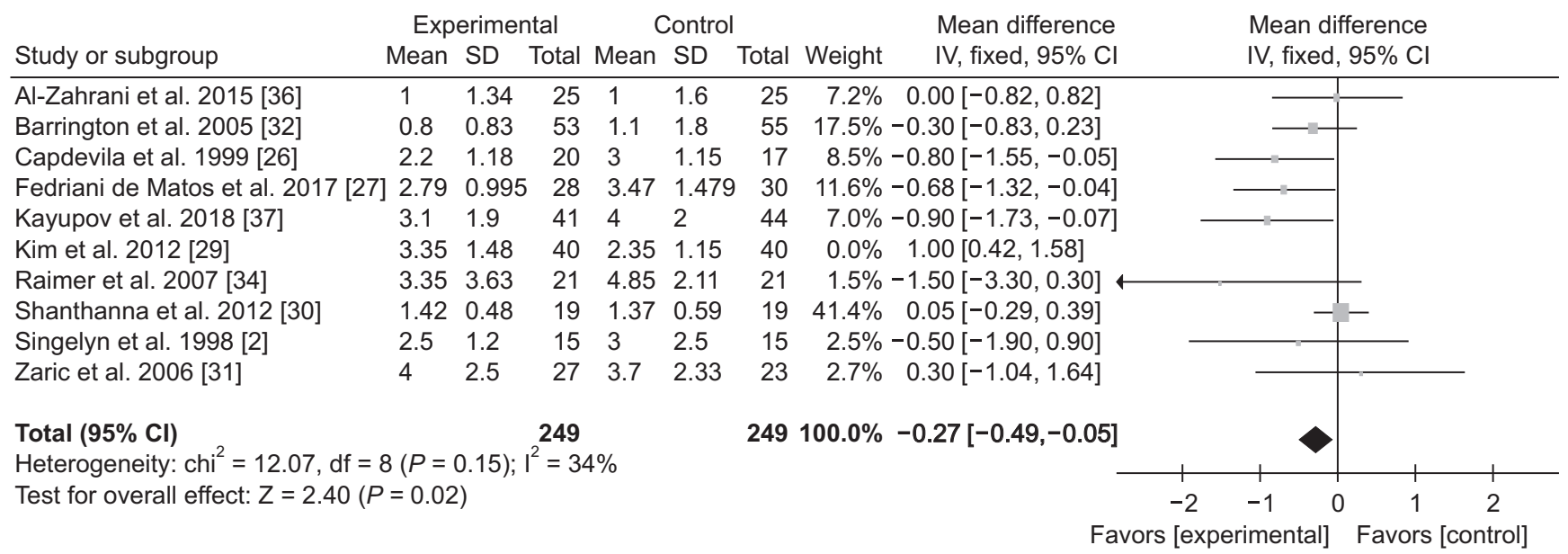

Fig. 10. Forest plot for the sensitivity analyses (24-48 hr). SD: standard deviation, IV: inverse variance, Cl: confidence interval, df: degree of freedom.

Table 6. Egger's test of the visual analogue scale score within $24-48$ hours

\begin{tabular}{lrrrrr}
\hline Std_Eff & Coef. & Std. Err. & $t$ & $P>\mid \mathrm{t}$ l & $95 \% \mathrm{Cl}$ \\
\hline Slope & 5.267 & 2.007 & 2.62 & 0.232 & $-20.239,30.773$ \\
Bias & -24.465 & 7.378 & -3.32 & 0.186 & $-118.208,69.277$ \\
\hline
\end{tabular}

Std_Eff: standardized effect, Coef.: coefficient, Std. Err.: standard error, Cl: confidence interval.

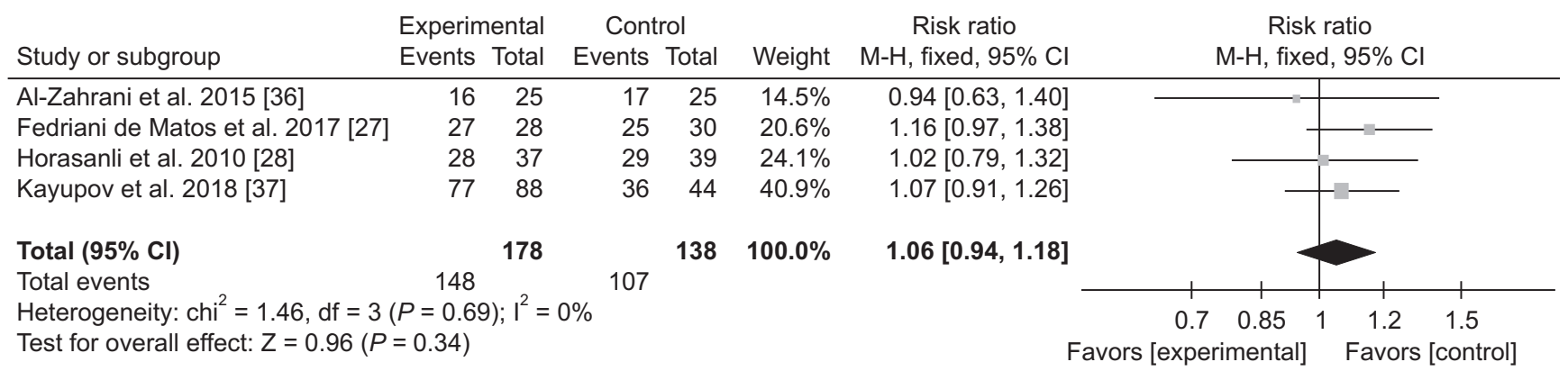

Fig. 11. Forest plot for patient satisfaction after nerve block vs. epidural block. M-H: Mantel-Haenszel, Cl: confidence interval, df: degree of freedom.

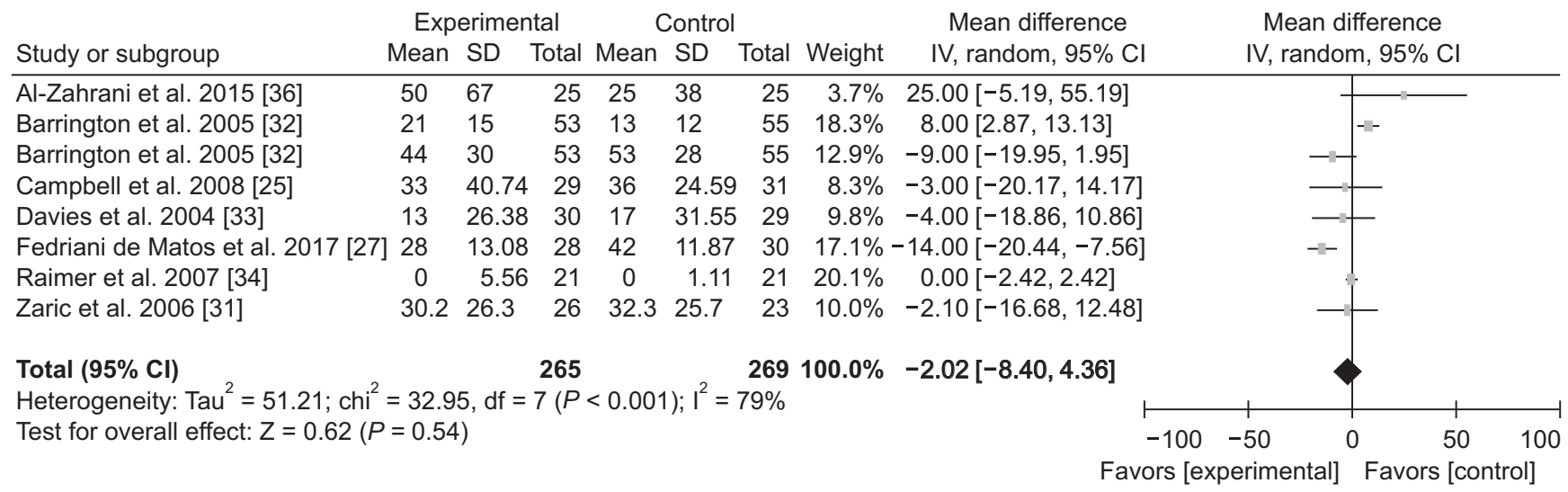

Fig. 12. Forest plot for intraoperative opioid use. SD: standard deviation, IV: inverse variance, Cl: confidence interval, df: degree of freedom. 


\begin{tabular}{|c|c|c|c|c|c|c|c|c|c|}
\hline \multirow[b]{2}{*}{ Study or subgroup } & \multicolumn{3}{|c|}{ Experimental } & \multicolumn{3}{|c|}{ Control } & \multirow{2}{*}{\multicolumn{2}{|c|}{$\begin{array}{l}\text { Mean difference } \\
\text { IV, fixed, } 95 \% \mathrm{Cl}\end{array}$}} & \multirow{2}{*}{$\begin{array}{l}\text { Mean difference } \\
\mathrm{IV} \text {, fixed, } 95 \% \mathrm{Cl}\end{array}$} \\
\hline & Mean & SD & Total & Mean & SD & Total & & & \\
\hline Barrington et al. 2005 [32] & 5.3 & 1.1 & 53 & 5.4 & 1.1 & 55 & $76.2 \%$ & $-0.10[-0.51,0.31]$ & \\
\hline Campbell et al. 2008 [25] & 6 & 1.48 & 29 & 6 & 2.22 & 31 & $14.6 \%$ & $0.00[-0.95,0.95]$ & \\
\hline Capdevila et al. 1999 [26] & 40 & 7.25 & 20 & 37 & 3.75 & 17 & $1.0 \%$ & $3.00[-0.64,6.64]$ & \\
\hline Davies et al. 2004 [33] & 7 & 1.5 & 30 & 8 & 3.7 & 29 & $6.2 \%$ & $-1.00[-2.45,0.45]$ & - \\
\hline Raimer et al. 2007 [34] & 11 & 0.25 & 21 & 12 & 1 & 21 & & Not estimable & \\
\hline Singelyn et al. 1998 [2] & 17 & 3 & 15 & 16 & 4 & 15 & $2.0 \%$ & $1.00[-1.53,3.53]$ & \\
\hline \multirow{2}{*}{\multicolumn{9}{|c|}{$\begin{array}{l}\text { Total }(95 \% \mathrm{Cl}) \\
\text { Heterogeneity: } \text { chi }^{2}=5.03, \mathrm{df}=4(P=0.28) ; I^{2}=20 \% \\
\text { Test for overall effect: } Z=0.48(P=0.63)\end{array}$}} & \\
\hline Test for overall effect: $Z=0$ & & & & & & & & & $\begin{array}{ccccc}2 & -1 & 0 & 1 & 2 \\
\text { rimental] } & \text { Favors [control] }\end{array}$ \\
\hline
\end{tabular}

Fig. 13. Forest plot for sensitivity analyses of the length of hospital stay. SD: standard deviation, IV: inverse variance, Cl: confidence interval, df: degree of freedom.

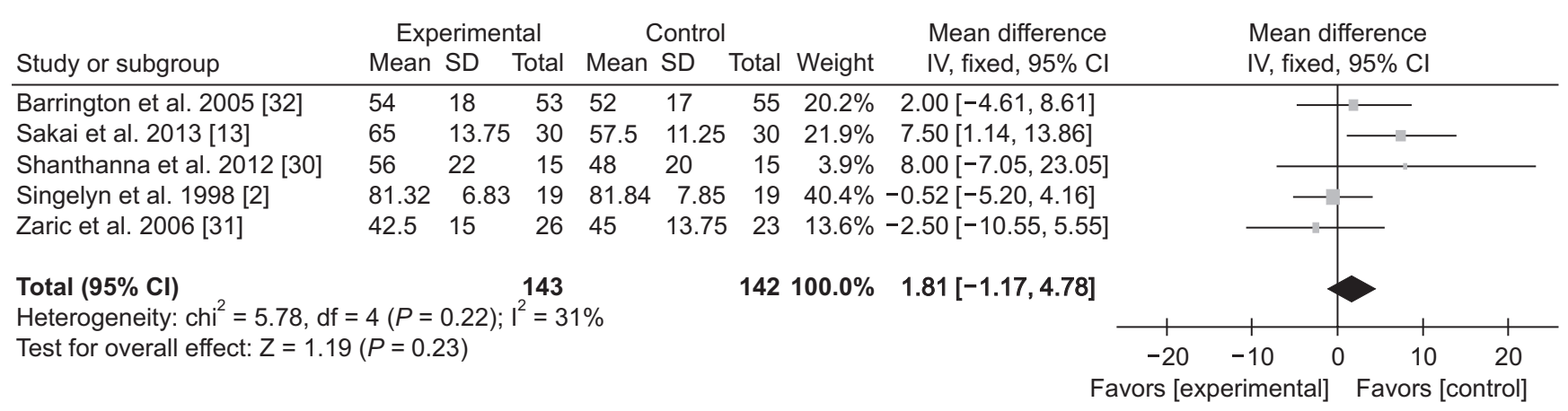

Fig. 14. Forest plot for active knee flexion after nerve block vs. epidural analgesia. SD: standard deviation, IV: inverse variance, Cl: confidence interval, df: degree of freedom.

\section{5) Length of hospital stay}

Six studies $[2,25,26,32-34]$ involving 336 patients reported the length of hospital stay, with 168 in the experimental group, and 168 in the control group. There was amongstudy heterogeneity $\left(I^{2}=66 \%, P=0.01\right)$; therefore, the random-effect model was used. Hospital stay in the experimental group was insignificantly shorter than in the control group (SMD $=-0.31,95 \% \mathrm{CI}[-0.96$ to 0.34$], P=0.35$ ) (Supplementary Fig. 7). Sensitivity analysis revealed that after removing the study by Raimer et al. [34], $I^{2}$ decreased to $20 \%$ without changing the conclusion (SMD $=-0.09,95 \%$ CI [-0.45 to 0.27 ], $P=0.63$ ) (Fig. 13). Subgroup analysis did not indicate between-subgroup heterogeneity $\left(I^{2}=0 \%, P\right.$ $=0.42$ ), which suggests there is little correlation between the heterogeneity source and the anesthesia mode. The heterogeneity source, however, could not be determined (Supplementary Fig. 8). The quality of the evidence was determined as being of a low grade by the GRADE Profile (Supplementary Table 5).

\section{6) Active knee flexion}

Five studies [2,13,30-32] involving 285 patients reported on active knee flexion, with 143 in the experimental group, and 142 in the control group. There was low among-study heterogeneity $\left(I^{2}=31 \%, P=0.22\right)$; therefore, we used the fixed-effect model. There was no between-group difference in the active knee flexion (SMD $=1.81,95 \%$ CI [-1.17 to 4.78], $P=0.23$ ) (Fig. 14). The quality of the evidence was determined as being of a moderate grade by the GRADE Profile (Supplementary Table 5).

\section{DISCUSSION}

Our findings show that compared with epidural block, a peripheral nerve block can significantly reduce TKA postoperative complications. The analgesic effect is more distinct 24-48 hours after the surgery compared with the other assessed time slots. Significance differences in patient satisfaction, perioperative opioid dosage, length of hospital stay, and active knee flexion were not found between the two groups. There was low overall among-study heterogeneity, a high level of evidence, and no significant publication bias.

The incidence of postoperative complications is a major index when evaluating the anesthesia protocol. Zaric et al. [31] reported that first day post-TKA, there was an $87 \%$ probability of one or more adverse reactions, including 
nausea and vomiting, sedation, and pruritus. The complications rate was $35 \%$ in their experimental group. The present meta-analysis found that the experimental group had a significantly lower incidence of nausea and vomiting, hypotension, urinary retention, and pruritus than the control group. This is consistent with the results reported in several other studies [38-40]. First of all, it may be related to the wide range of epidural blocks [41]; moreover, using large doses of opioids could increase the incidence of nausea and vomiting [42]. Although there was no significant between-group difference in the opioid dosage, a lower dose is expected to lead to fewer side effects.

VAS scores are a common clinical evaluation index. In this meta-analysis, there was a significant between-group difference in the VAS scores only at 24-48 hours after the TKA. This suggests that the peripheral nerve block and the traditional analgesic method exhibit similar postoperative analgesic effects. This is consistent with several previous reports $[43,44]$. Sensitivity analysis of the VAS score findings at 0-12 hours revealed that the study by Singelyn et al. [2] was the source for the heterogeneity. Singelyn et al. [2] reported only the sample size and ASA grade; therefore, the age range, sex ratio, and body mass index could have contributed to the heterogeneity. Regarding the VAS score measured at 12-24 hours, neither sensitivity nor subgroup analysis could identify the source of heterogeneity; however, we assume that differences in patient selection and anesthetic concentration and dosage could have been major sources of heterogeneity. Upon analysis of the VAS score measured at 24-48 hours, a peripheral nerve block was found to reduce the VAS score after excluding the study by Kim et al. [29]. This could have resulted from the sex ratio in the study by Kim et al. [29], which was quite different from that of the other included studies.

Ritter et al. [45] compared the 5-year effect of TKA between 4,379 female and 2,947 male patients and reported a significantly lower VAS score among male patients. After removing this study from the analysis, there was a relative increase in the proportion of male patients in the experimental group. This change in sex ratio and the lower VAS score among male patients could have contributed to the reduced VAS score.

Several studies $[25,30]$ have reported that the femoral nerve block effect was not optimal during the 24 hours after the surgery since it does not block the sciatic and obturator nerves. Consequently, it was reported that the VAS score in the peripheral nerve block group was significantly higher than that of the epidural block group [37]. Long et al. [46], on the other hand, reported that the analgesic effect of peripheral nerve block was optimal within 24 hours after surgery. In this meta-analysis, there was no betweengroup difference in the VAS score measured within 24 hours after the TKA, which is consistent with the findings reported by Fowler et al. [39] and Gerrard et al. [40].

Our meta-analysis demonstrates a good analgesic effect from long-acting opioids, including morphine and fentanyl. Other analgesic methods for pain relief during the perioperative period exist. The side effects of opioids, including nausea, vomiting, urinary retention, and respiratory depression, might impede post-TKA patient rehabilitation. Although there was no significant between-group difference in opioid dosage, numerically, the experimental group received a lower opioid dose, which is reflected in the distribution of the side effects. In addition, although there was no between-group difference in patient satisfaction, it was numerically higher in the experimental group.

The ultimate goal of TKA is the postoperative recovery of a functional knee joint. In this meta-analysis, we found that the experimental group had slight but insignificant advantages in the length of hospital stay and active knee flexion. This is consistent with findings in several previous reports $[33,46]$. The study by Raimer et al. [34] was identified as the source of heterogeneity when analyzing the length of hospital stay. This could be attributed to their discharge policy rather than to the choice of anesthetics.

In this meta-analysis, the peripheral nerve block was found to exhibit advantages in patient satisfaction, perioperative opioid use, and rehabilitation indices. Moreover, it could be more effective than the epidural block in reducing postoperative complications. Importantly, nerve injury was not reported in any of the trials. Therefore, we conclude that peripheral nerve block may be an attractive alternative analgesic technique for knee arthroplasty patients.

\section{Strengths and limitation}

\section{1) Strengths}

This meta-analysis comprehensively evaluated the postTKA analgesic effect on adverse reactions, VAS score, patient satisfaction, and rehabilitation indices. Moreover, multiple indices were graded at a moderate or high evidence level. This indicates that the results are credible and provide strong evidence for clinical guidance.

\section{2) Limitations}

The drug type and dose, as well as the timing of drug use, differed across studies. Such differences could have affected the final index measurement. Moreover, due to the limited number of studies included, this article could only study all peripheral nerve block approaches grouped together. We could not separately analyze each nerve block 
type, which must have led to deviation of the results. In addition, high heterogeneity was found among studies in some measures, but sensitivity and subgroup analyses could not reveal its source. Finally, this study does not include more "novel" peripheral nerve blocks used for TKA, which reduces the richness of the article.

In conclusion, this meta-analysis compared peripheral nerve block to epidural block as a mode of anesthesia during TKA and for postoperative pain control. For knee joint replacement, a peripheral nerve block can effectively reduce the occurrence of complications and lead to higher patient satisfaction in the postoperative period. The peripheral nerve block shows good performance in all aspects. We performed a sensitivity analysis on its analgesic effect within 24 hours after surgery. Studies were excluded one by one with no change in the heterogeneity, indicating that there was no significant effect for the analgesic approach within 24 hours after the surgery on the analyzed outcomes. More large-scale, high-quality randomized controlled trials are needed to evaluate the optimal anesthetic method for knee joint replacement and draw more precise conclusions.

\section{CONFLICT OF INTEREST}

No potential conflict of interest relevant to this article was reported.

\section{FUNDING}

This study was supported by the Health Research Talent Special Project (No. 2019SCZ026) and Province Science and Technology Development Plan Project (No. 20160101121JC).

\section{ORCID}

Di You, https://orcid.org/0000-0002-2606-6521

Lu Qin, https://orcid.org/0000-0001-7621-250X

Kai Li, https://orcid.org/0000-0002-9342-8836

Di Li, https://orcid.org/0000-0001-7766-5092

Guoqing Zhao, https://orcid.org/0000-0002-5672-4273

Longyun Li, https://orcid.org/0000-0003-1630-4298

\section{SUPPLEMENTARY MATERIALS}

Supplementary materials can be found via https://doi. org/10.3344/kjp.2021.34.3.271.

\section{REFERENCES}

1. Kester BS, Minhas SV, Vigdorchik JM, Schwarzkopf R. Total knee arthroplasty for posttraumatic osteoarthritis: is it time for a new classification? J Arthroplasty 2016; 31: 1649-53.el.

2. Singelyn FJ, Deyaert M, Joris D, Pendeville E, Gouverneur JM. Effects of intravenous patient-controlled analgesia with morphine, continuous epidural analgesia, and continuous three-in-one block on postoperative pain and knee rehabilitation after unilateral total knee arthroplasty. Anesth Analg 1998; 87: 88-92.

3. Ibrahim MS, Khan MA, Nizam I, Haddad FS. Peri-operative interventions producing better functional outcomes and enhanced recovery following total hip and knee arthroplasty: an evidence-based review. BMC Med 2013; 11: 37.

4. Webb CA, Mariano ER. Best multimodal analgesic protocol for total knee arthroplasty. Pain Manag 2015; 5: 185-96.

5. Wheatley RG, Shepherd D, Jackson IJ, Madej TH, Hunter D. Hypoxaemia and pain relief after upper abdominal surgery: comparison of i.m. and patient-controlled analgesia. Br J Anaesth 1992; 69: 558-61.

6. Moen V, Dahlgren N, Irestedt L. Severe neurological complications after central neuraxial blockades in Sweden 19901999. Anesthesiology 2004; 101: 950-9.

7. Zinkus J, Mockutè L, Gelmanas A, Tamošiūnas R, Vertelis A, Macas A. Comparison of 2 analgesia modalities in total knee replacement surgery: is there an effect on knee function rehabilitation? Med Sci Monit 2017; 23: 3019-25.

8. Runge C, Børglum J, Jensen JM, Kobborg T, Pedersen A, Sandberg J, et al. The analgesic effect of obturator nerve block added to a femoral triangle block after total knee arthroplasty: a randomized controlled trial. Reg Anesth Pain Med 2016; 41: 445-51.

9. Macrinici GI, Murphy C, Christman L, Drescher M, Hughes B, Macrinici V, et al. Prospective, double-blind, randomized study to evaluate single-injection adductor canal nerve block versus femoral nerve block: postoperative functional outcomes after total knee arthroplasty. Reg Anesth Pain Med 2017; 42: 10-6.

10. Elkassabany NM, Antosh S, Ahmed M, Nelson C, Israelite C, Badiola I, et al. The risk of falls after total knee arthroplasty with the use of a femoral nerve block versus an adductor canal block: a double-blinded randomized controlled study. Anesth Analg 2016; 122: 1696-703.

11. Sundarathiti P, Ruananukul N, Channum T, Kitkunasathean C, Mantay A, Thammasakulsiri J, et al. A comparison of continuous femoral nerve block (CFNB) and continuous epidural infusion (CEI) in postoperative analgesia and knee rehabilitation after total knee arthroplasty (TKA). J Med Assoc Thai 2009; 92: 328-34.

12. Osawa M, Takahama Y, Kondo Y. [Comparison of postoperative pain relief by continuous femoral nerve block and that 
by epidural block during physiotherapy after minimally invasive surgery of total knee arthroplasty and uni-condylar knee arthroplasty]. Masui 2012; 61: 1316-23. Japanese.

13. Sakai N, Inoue T, Kunugiza Y, Tomita T, Mashimo T. Continuous femoral versus epidural block for attainment of $120^{\circ}$ knee flexion after total knee arthroplasty: a randomized controlled trial. J Arthroplasty 2013; 28: 807-14.

14. Moher D, Liberati A, Tetzlaff J, Altman DG. Preferred reporting items for systematic reviews and meta-analyses: the PRISMA statement. Int J Surg 2010; 8: 336-41.

15. Shoji H, Solomonow M, Yoshino S, D’Ambrosia R, Dabezies E. Factors affecting postoperative flexion in total knee arthroplasty. Orthopedics 1990; 13: 643-9.

16. Ryu J, Saito S, Yamamoto K, Sano S. Factors influencing the postoperative range of motion in total knee arthroplasty. Bull Hosp Jt Dis 1993; 53: 35-40.

17. Naylor JM, Walker R. Low value care and inpatient rehabilitation after total knee replacement. Med J Aust 2018; 209: 207-8.

18. Kuo AC, Raghunathan K, Lartigue AM, Bryan WE 3rd, Pepin MJ, Takemoto S, et al. Freedom from opioids after total knee arthroplasty. J Arthroplasty 2019; 34: 893-7.

19. Roberts KC, Moser SE, Collins AC, McCardel BR, Schultz KA, Schaffer NE, et al. Prescribing and consumption of opioids after primary, unilateral total hip and knee arthroplasty in opioid-naive patients. J Arthroplasty 2020; 35: 960-5.el.

20. Higgins JPT, Altman DG. Assessing risk of bias in included studies. In: Cochrane handbook for systematic reviews of interventions: Cochrane book series. Edited by Higgins JPT, Green S. Chichester, John Wiley \& Sons. 2008, pp 187-241.

21. Hou X, Shi J, Chen X. How to estimate the mean and standard deviation based on the median, range and sample size when conducting meta-analysis. Chin J Evid Based Med 2015; 15: 484-7.

22. Jüni $P$, Altman DG, Egger M. Assessing the quality of randomised controlled trials. In: Systematic reviews in health care: meta-analysis in context. 2nd ed. Edited by Egger M, Smith GD, Altman DG. London, BMJ. 2008, pp 87-108.

23. Higgins JP, Thompson SG, Deeks JJ, Altman DG. Measuring inconsistency in meta-analyses. BMJ 2003; 327: 557-60.

24. Adams HA, Saatweber P, Schmitz CS, Hecker H. Postoperative pain management in orthopaedic patients: no differences in pain score, but improved stress control by epidural anaesthesia. Eur J Anaesthesiol 2002; 19: 658-65.

25. Campbell A, McCormick M, McKinlay K, Scott NB. Epidural vs. lumbar plexus infusions following total knee arthroplasty: randomized controlled trial. Eur J Anaesthesiol 2008; 25: 502-7.

26. Capdevila X, Barthelet Y, Biboulet P, Ryckwaert Y, Rubenovitch J, d'Athis F. Effects of perioperative analgesic technique on the surgical outcome and duration of rehabilitation after major knee surgery. Anesthesiology 1999; 91: 8-15.
27. Fedriani de Matos JJ, Atienza Carrasco FJ, Díaz Crespo J, Moreno Martín A, Tatsidis Tatsidis P, Torres Morera LM. Effectiveness and safety of continuous ultrasound-guided femoral nerve block versus epidural analgesia after total knee arthroplasty. Rev Esp Anestesiol Reanim 2017; 64: 79 85.

28. Horasanli E, Gamli M, Pala Y, Erol M, Sahin F, Dikmen B. A comparison of epidural anesthesia and lumbar plexus-sciatic nerve blocks for knee surgery. Clinics (Sao Paulo) 2010; 65: 29-34.

29. Kim JH, Cho MR, Kim SO, Kim JE, Lee DK, Roh WS. A comparison of femoral/sciatic nerve block with lateral femoral cutaneous nerve block and combined spinal epidural anesthesia for total knee replacement arthroplasty. Korean J Anesthesiol 2012; 62: 448-53.

30. Shanthanna H, Huilgol M, Manivackam VK, Maniar A. Comparative study of ultrasound-guided continuous femoral nerve blockade with continuous epidural analgesia for pain relief following total knee replacement. Indian J Anaesth 2012; 56: 270-5.

31. Zaric D, Boysen K, Christiansen C, Christiansen J, Stephensen S, Christensen B. A comparison of epidural analgesia with combined continuous femoral-sciatic nerve blocks after total knee replacement. Anesth Analg 2006; 102: 1240-6.

32. Barrington MJ, Olive D, Low K, Scott DA, Brittain J, Choong P. Continuous femoral nerve blockade or epidural analgesia after total knee replacement: a prospective randomized controlled trial. Anesth Analg 2005; 101: 1824-9.

33. Davies AF, Segar EP, Murdoch J, Wright DE, Wilson IH. Epidural infusion or combined femoral and sciatic nerve blocks as perioperative analgesia for knee arthroplasty. Br J Anaesth 2004; 93: 368-74.

34. Raimer C, Priem K, Wiese AA, Birnbaum J, Dirkmorfeld LM, Mossner A, et al. Continuous psoas and sciatic block after knee arthroplasty: good effects compared to epidural analgesia or i.v. opioid analgesia: a prospective study of 63 patients. Acta Orthop 2007; 78: 193-200.

35. Chelly JE, Greger J, Gebhard R, Coupe K, Clyburn TA, Buckle $\mathrm{R}$, et al. Continuous femoral blocks improve recovery and outcome of patients undergoing total knee arthroplasty. J Arthroplasty 2001; 16: 436-45.

36. Al-Zahrani T, Doais KS, Aljassir F, Alshaygy I, Albishi W, Terkawi AS. Randomized clinical trial of continuous femoral nerve block combined with sciatic nerve block versus epidural analgesia for unilateral total knee arthroplasty. J Arthroplasty 2015; 30: 149-54.

37. Kayupov E, Okroj K, Young AC, Moric M, Luchetti TJ, Zisman $\mathrm{G}$, et al. Continuous adductor canal blocks provide superior ambulation and pain control compared to epidural analgesia for primary knee arthroplasty: a randomized, controlled trial. J Arthroplasty 2018; 33: 1040-4.el.

38. Gandhi HJ, Trivedi LH, Tripathi DC, Dash DM, Khare AM, 
Gupta MU. A randomized, controlled trial of comparison of a continuous femoral nerve block (CFNB) and continuous epidural infusion (CEI) using $0.2 \%$ ropivacaine for postoperative analgesia and knee rehabilitation after total knee arthroplasty (TKA). J Anaesthesiol Clin Pharmacol 2019; 35: 386-9.

39. Fowler SJ, Symons J, Sabato S, Myles PS. Epidural analgesia compared with peripheral nerve blockade after major knee surgery: a systematic review and meta-analysis of randomized trials. Br J Anaesth 2008; 100: 154-64.

40. Gerrard AD, Brooks B, Asaad P, Hajibandeh S, Hajibandeh S. Meta-analysis of epidural analgesia versus peripheral nerve blockade after total knee joint replacement. Eur J Orthop Surg Traumatol 2017; 27: 61-72.

41. Yuan Z, Wei J, Wen J, Yang S, Quan D. A meta-analysis of countious femoral nerve block versus continuous epidural analgesia after total knee arthroplasty. Chin J Tissue Eng Res 2015; 19: 5728-34.

42. Zywiel MG, Stroh DA, Lee SY, Bonutti PM, Mont MA. Chronic opioid use prior to total knee arthroplasty. J Bone Joint Surg Am 2011; 93: 1988-93.

43. Patel N, Solovyova O, Matthews G, Arumugam S, Sinha SK, Lewis CG. Safety and efficacy of continuous femoral nerve catheter with single shot sciatic nerve block vs epidural catheter anesthesia for same-day bilateral total knee arthroplasty. J Arthroplasty 2015; 30: 330-4.

44. Patterson ME, Bland KS, Thomas LC, Elliott CE, Soberon JR Jr, Nossaman BD, et al. The adductor canal block provides effective analgesia similar to a femoral nerve block in patients undergoing total knee arthroplasty--a retrospective study. J Clin Anesth 2015; 27: 39-44.

45. Ritter MA, Wing JT, Berend ME, Davis KE, Meding JB. The clinical effect of gender on outcome of total knee arthroplasty. J Arthroplasty 2008; 23: 331-6.

46. Long WT, Ward SR, Dorr LD, Raya J, Boutary M, Sirianni LE. Postoperative pain management following total knee arthroplasty: a randomized comparison of continuous epidural versus femoral nerve infusion. J Knee Surg 2006; 19: 137-43. 